Ann N Y Acad Sci. 2012 February ; 1248: 1-17. doi:10.1111/j.1749-6632.2011.06298.x.

\title{
The clinical significance of drug craving
}

\author{
Stephen T. Tiffany and Jennifer M. Wray \\ Department of Psychology, University at Buffalo, The State University of New York, Buffalo, New \\ York
}

\begin{abstract}
Although drug craving has received considerable research attention over the past several decades, to date there has been no systematic review of the general clinical significance of craving. This paper presents an overview of measurement issues of particular relevance to a consideration of use of craving in clinical settings. The paper then considers the relevance of craving across a broad array of clinical domains, including diagnosis, prognostic utility, craving as an outcome measure, and the potential value of craving as a direct target of intervention. The paper is both descriptive and prescriptive, informed by the current state of the science on craving with recommendations for the definition of craving, assessment practices, future research, and clinical applications. We conclude that craving has considerable utility for diagnosis and as a clinical outcome, and that findings from future research will likely expand the clinical potential of the craving construct in the domains of prognosis and craving as a treatment target.
\end{abstract}

\section{Keywords}

craving; clinical significance; diagnosis; prognosis; clinical outcomes

\section{Introduction}

Over the past 40 years, drug craving has been a highly lively and, at times, contentious topic. Craving disputes have erupted over the definition of the word craving, the measurement of craving, the function of craving in addiction, and the utility of craving for understanding addictive processes. ${ }^{1-4}$ These disputes have occurred in the context of a voluminous and rapidly expanding literature on craving. Over the past 50 years, approximately 10,000 articles have been published on craving - more than $60 \%$ of these have appeared in just the past 10 years. ${ }^{a}$ The significance of craving is considerably less controversial among those who are addicted. For these people, craving is a very real phenomenon. It often intrudes into their daily lives, at times dominating their thoughts and generating considerable distress. Although there have been several reviews covering the

\footnotetext{
(C) 2012 New York Academy of Sciences.

Address for correspondence: Stephen T. Tiffany, Ph.D., Empire Innovation Professor, Chair, Department of Psychology, Park 206, University at Buffalo, The State University of New York, Buffalo, NY 14260. stiffany @ buffalo.edu.

Conflicts of interest

The authors declare no conflicts of interest.

${ }^{a}$ Estimates generated through MEDLINE and PsychINFO search for Abstracts containing the terms crave or craving.
} 
basic science and theory of craving ${ }^{5}$ or the clinical relevance of certain features of craving for select drugs of abuse, ${ }^{6-8}$ there have been no comprehensive examinations of the overall clinical significance of craving across substance-use disorders.

An issue that has received considerable attention in the clinical realm is the extent to which craving is or is not related to drug use and relapse. ${ }^{9-12}$ Though this is an important concern, we believe the potential clinical utility of craving extends beyond this somewhat narrow question. Thus, this paper will review the relevance of craving across a broader array of clinical domains including diagnosis, prognostic utility, craving as an outcome measure, and the potential value of craving as a direct target of intervention. The paper will be both descriptive and prescriptive, with recommendations informed by the current state of the science on craving. We will start, however, with a discussion of the measurement of craving, as we believe that a full consideration of selected assessment issues will set the stage for a more informative review of related clinical topics.

\section{Craving assessment}

The clinical utility of drug craving is governed, in part, by the psychometric adequacy of craving measures. But despite the development of several psychometrically validated multiitem craving instruments, craving continues to be assessed most commonly with single-item ratings in both clinical and research settings. ${ }^{13,14}$ To date, the measurement of craving has been highly uneven - there are no field-wide (or drug-specific) standard instruments for craving assessment. ${ }^{14}$ In some research areas, certain measures have been used so frequently that they have emerged as de facto standards. For example, the Questionnaire on Smoking Urges-Brief (QSU-Brief ${ }^{15}$ ) and the Obsessive Compulsive Drinking Scale (OCDS ${ }^{16}$ ) are the most commonly used multi-item craving instruments in their respective fields.

Multiple reviews have addressed a range of issues relevant to craving assessment. ${ }^{14,17-20}$ Several themes emerge across these reviews including the nearly universal idea that craving is best indexed through self-report instruments, that many instruments across all the major drug-use disorders are able to yield highly reliable craving scores, that craving has only a modest relationship with measures of drug use, and that analyses of the latent structure of multi-item craving measures suggest that craving is primarily (though not exclusively) a unidimensional construct. ${ }^{b}$

\section{Definitions of craving}

The particular definition of craving represented on any craving instrument is derived from an explicit or implicit conceptualization of the nature of drug craving and its role in addictive processes. Nearly all modern comprehensive theories of addiction propose that craving is relevant to understanding drug motivation, and there are several theories that discuss in great detail the sources of craving, craving processes, and the impact of craving in substance-use disorders. ${ }^{5}$ The fact that craving is such a central concept in addictions

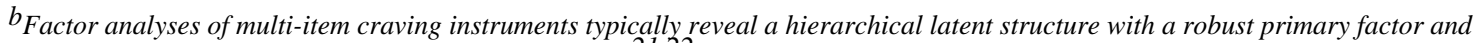
two or more strongly intercorrelated first-order factors. ${ }^{21,22}$
} 
research suggests that most researchers believe that craving is real- that is, it is an attribute that exists outside of any particular theory of craving.

With regard to the adequacy of assessment, the most immediate issue for the clinician (or researcher, for that matter) is whether a craving as sessment measures what it is supposed to measure. ${ }^{23}$ That is, do variations in craving produce systematic variations in performance on a craving assessment? ${ }^{24}$ The answer to that question requires some idea of the presumptive core characteristics of craving that need to be captured by craving assessments. Despite the diversity of craving theories, most researchers assume that craving is a subjective experience of wanting to use a drug. ${ }^{5,8}$ This definition has three distinct elements: craving is conscious, craving is best captured by an expression of desire, and that desire is directed toward the use of a specific drug.

Of these three elements, the one that has generated some debate is the idea that craving is necessarily conscious. For example, according to an animal-based model of addiction motivation, ${ }^{25}$ the "wanting" system, which is the hypothesized substrate of craving (and compulsive drug seeking), operates primarily at implicit, unconscious levels and only occasionally intrudes into conscious awareness. We believe the immediate clinical implications of the possibility of "unconscious craving" are somewhat limited. First, this specific hypothesis has yet to be tested, and, judging by the prevailing view in the field regarding the salience of conscious craving, not likely to gain much traction in the absence of more clearly specified mechanisms for how and under what conditions implicit, unconscious "wanting" processes are translated into explicit, conscious craving. Second, even if conscious craving were only the tip of the craving iceberg, it is not evident how, given the current state of our knowledge, a clinician could capture unconscious craving without relying on some explicit, self-report measure reflecting a drug user's experience of craving. To date, there are no known implicit, nonverbal manifestations of craving that are tightly coupled to self-report craving. ${ }^{14,19}$ Nonverbal measures may ultimately be identified that are associated strongly withself-reportedcraving.Forexample,undersome conditions, regional brain activation as revealed by neuroimaging can be significantly associated with craving report. ${ }^{26-28}$ Most of this research has used a cue-reactivity paradigm in which drug users' reactions to drug-related cues are contrasted with their reactions to neutral cues, with the resulting changes in brain activity correlated with craving ratings. In general, these studies suggest that drug-related cues primarily activate cortical regions related to a broad range of functioning including processing of reward, memory, motivation, regulation of action, executive control, affect, and interoceptive integration. ${ }^{29,30}$ Although such findings may ultimately tell us a great deal about the neurobiological associates of craving, the magnitude of the correlations between brain activity and craving report are, to date, not sufficiently or consistently robust to indicate that neuroimaging is ready to offer a clinically viable biomarker for craving report. Moreover, a measure of craving has to be clinically practical with wide applicability across a diverse range of clinical settings. Our technology has not advanced to the point where neuroimaging offers a feasible approach for routine assessment of craving in clinical practice. 


\section{Content of craving assessments}

The standard definition of craving suggests that craving assessments should include items referring directly to the concept of desire. Not surprisingly, many craving assessments use terms such as desire, want, urge, need, or closely related synonyms. Some assessments ask people to rate their level of craving, though the term craving is not included in many popular instruments. For example, Table 1 shows items from major diagnostic assessments used in the addictions field that purportedly index craving. Notably, none of these instruments actually uses the term craving. The absence of craving as an item is not limited to these examples. Neither the QSU-Brief ${ }^{15}$ nor the OCDS, ${ }^{16}$ which, as described earlier, are two commonly used multi-item measures of craving in the tobacco and alcohol fields, respectively, include the word crave or craving in their item sets. This is not a trivial pointin its approval of varenicline for the treatment of cigarette smoking, the Food and Drug Administration (FDA) allowed the drug to be advertised as reducing the urge to smoke but not as reducing craving, primarily because the QSU-Brief, which was used in a majority of the research examining the effects of the drug on craving, did not include an item specifically referencing craving. ${ }^{3}{ }^{c}$

Must an assessment use the word craving in order to measure craving? We can find little justification, empirical or conceptual, for this claim. There are many seminal self-report assessments used in psychiatry and psychology that do not include items directly addressing the construct purportedly measured by the instruments. For instance, the Beck Depression Inventory ${ }^{32}$ does not include any items that mentionthe term depression. With regardto craving assessment, there is no indication from psychometric analyses of craving measures that the term craving is semantically distinct from any other terms referring to desire. $1,33,34$ That is, on average, drug users appear to use the word craving to mean the same thing as captured by other synonyms of desire. Consequently, an instrument that asks people to rate their level of desire for a drug, or some common synonym of desire, likely qualifies as directly addressing the concept of craving even though it might not specifically use the word craving.

A broader question is whether an instrument must use items referring to some form of desire to qualify as a craving measure. The OCDS, ${ }^{16}$ which has been described by its developers as a measure of craving for alcohol, contains no terms that would be considered common synonyms of desire. Various analyses of the latent structure of this instrument suggest the items reflect a variety of factors including obsessive thoughts about alcohol, interference with functioning, automaticity of drinking, and attempts to control drinking and obsessions. ${ }^{35-38}$ But none of these analyses revealed any factor that might be construed as desire. Also, some studies have examined associations between the OCDS and other measures of alcohol craving that do include explicit desire items. ${ }^{39,40}$ The pattern of results across these studies suggests that the OCDS is not as strongly correlated with these other measures as one might expect if this questionnaire was primarily capturing a dimension of alcohol desire common across craving measures. There are other examples of craving questionnaires that do not appear to include any items reflecting the desire to use drugs. ${ }^{41-43}$

${ }^{c}$ The FDA position also resurrected an old assertion by Kozlowski and Wilkinson ${ }^{1}$ that the term craving be restricted to the extreme end of the desire continuum. 1 
Given that the conventional definition of craving is a desire for a drug, it is questionable whether questionnaires without items directly addressing desire adequately represent the craving construct.

Multi-item craving questionnaires often contain items that go beyond synonyms of desire and address a diverse range of content including items asking about intentions to use, expectancies that use will lead to specific outcomes (e.g., increase positive mood or decrease negative mood and withdrawal), or lack of control over use. ${ }^{15,16,18}$ The customary argument for this additional item content is that craving has multidimensional facets that extend beyond the category of desire. ${ }^{19}$ Some have criticized this expanded content as unnecessary for capturing the essence of craving, and have noted particularly that some categories of items, for example, expectancies, are both conceptually and empirically distinguishable from desire. ${ }^{33,50} \mathrm{We}$ think that multicategory craving instruments are extremely useful for basic research on the mechanisms that generate craving responses and explorations of the network of relationships between traditional expressions of craving and craving-related constructs. ${ }^{19,51}$ Moreover, some content appears to be closely linked to statements of desire. Importantly, factor analytic research has shown consistently that items tapping intentions to use (e.g., "I plan to smoke a cigarette as soon as possible") nearly always end up on the same factor as desire items, suggesting that desire and intention may occupy the same semantic space, ${ }^{22,34}$ particularly for users who are not trying to abstain. On the other hand, some instruments often have many more items than are strictly necessary for simply assessing the desire to use a drug. These considerations are particularly critical in clinical settings, where shorter, more focused instruments would be preferred.

\section{Dynamics of craving}

For most people with substance-use disorders, craving is a dynamic phenomenon, displaying peaks, valleys, and short duration spikes over the course of any given day. ${ }^{2,8}$ Nearly all craving assessments focus on the strength of craving - very few measures have been developed to evaluate the frequency or duration of craving bouts. One exception is the Penn Alcohol Craving Scale (PACS), 52 which includes items assessing the frequency of thoughts about alcohol, the time spent thinking about drinking, and the strength of craving at the most severe point over the previous week (see Halikas et al. ${ }^{53}$ for a similar approach to cocaine craving). These three features are summed (along with ratings from two other cravingrelated items) to generate a composite cravingscore.Presumably, thiscompositerepresents an integration of craving (or area under the curve) for total craving experienced over the past week, although the extent to which this instrument actually captures profiles of craving over time is unclear. Information about frequency and duration may increase the clinical yield of craving assessments over and above instruments that only target craving intensity. However, as of yet, there has been neither programmatic research examining the incremental utility of these additional features of craving nor is it evident that a retrospective assessment of craving can accurately replicate the time-dependent dynamics of craving.

\section{Conditions of craving assessment}

As a general rule, the clinical utility of any assessment is maximized when the conditions of instrument development and clinical implementation are matched. Craving can vary 
considerably as a function of numerous contextual and intraindividual factors including the presence of drug-related cues, theavailabilityofdrug,theassessmentenvironment, the age of the user, the treatment status of the user, and the phase of treatment. ${ }^{8,21}$ These factors can influence both the strength of craving and the pattern of associations of craving with other addiction-relevant variables. This plasticity suggests that a craving assessment developed and evaluated under one set of conditions may not have the same operating characteristics under other conditions. From a clinical perspective, it is useful to know that some craving assessments have been developed with samples of drug users who were not seeking treatment ${ }^{22}$ or with samples restricted to inpatients. ${ }^{54}$ Further, with only a few exceptions, ${ }^{55}$ most instruments have been developed with adults. Craving instruments might be somewhat invariant across variations in contexts or groups of users, but there has been little systematic research on this issue.

A useful distinction when evaluating craving assessments is the extent to which the craving measure reflects tonic or phasic shifts in desire for drug. ${ }^{8}$

Toniccravingisexpressedasaslowlychangingsignal that may reflect abstinence or withdrawalrelated craving. Phasic craving reflects fast onset but rel atively short duration spikes in craving level that arises in response to drug-related cues that have previously been paired with drug administration. This cue-specific craving occurs when drug users are confronted with environmental cues or emotionally charged stimuli that remind the person of previous episodes of use or signal an impending occasion for drug use. Much laboratory-based craving research has focused on phasic, cue-specific craving, but the extent to which the clinical features and correlates of this form of craving are the same as those associated with tonic or deprivation-based craving has not been clearly established.

\section{Reliability of craving assessments}

Thereliabilityofacravingmeasureistheconsistency of scores generated by repeated administrations of the measure across identical conditions. Reliability, which can be thought of as the precision of a measure, cannot be calculated; it can only be estimated, and those estimates can only be generated with craving measures having two or more items. High reliability is beneficial-a more reliable score offers the opportunity for greater clinical utility. It is not unusual to obtain reliability estimates from multi-item craving instruments of 0.90 or greater, a level of reliability at the high end of most behavioral assessments. ${ }^{56}$ Craving scores with reliability well below 0.90 , which may be inadequate for clinical applications, ${ }^{57}$ indicates that the instrument could be improved (or replaced). Several factors can enhance the reliability of any measure of craving including the intercorrelation of the items contributing to the craving score, the number of quality items contributing to the total score, the unidimensionality of the item set, the distribution of craving, and the range of craving. ${ }^{18}$

Reliability is not, as sometimes portrayed, an immutable property of an instrument but rather reflects a confluence of the properties of the instrument, characteristics of the people completing the instrument, and conditions of testing. ${ }^{58}$ Clinically, this means that an estimate of reliability may not be portable from a validation study to a clinical setting, and it is possible that reliability in clinical situations would be considerably lower than published 
validation figures. Reliability is most likely to be attenuated when the range of craving scores is restricted; ${ }^{59}$ for example, reliability in samples with very high or very low levels of craving will almost certainly be reduced relative to a sample with a full range of craving scores. Unfortunately, reliability estimates are rarely reported in published research, or, if they are included, the estimate often comes from a prior validation study and not from the sample used in the research. Ideally, researchers would always report a reliability estimate for their craving measures, especially when craving is a major variable in the investigation. And, given that reliability may not be generalizable across studies, that estimate should be generated from the sample used in the research study.

\section{Stability of craving state versus trait distinction}

To the extent that craving fluctuates over time and settings, repeated measures of craving should generate correspondingly low estimates of stability. Indeed, test-retest studies of craving generally produce lower estimates of stability than the reliability estimates (i.e., internal consistency coefficients) produced in the same samples. ${ }^{35,39,60,61}$ Though low stability may be characteristic of a momentary state of craving, there are times when a highly stable estimate of craving is preferable. For example, some researchers have attempted to determine whether cue-specific craving assessed prior to a quit attempt is predictive of subsequent relapse. ${ }^{11}$ When we assess cue reactivity at some point distal to relapse episodes, the implicit assumption is that the assessment indexes a stable, somewhat invariant component of cue-specific craving - a component that exerts influence across time and contexts, and has, hypothetically, a pervasive impact on relapse risk. Under these conditions, cue-specific craving would be considered a trait, and we would want to be certain that our assessment captured stable individual differences in craving responses. It is unlikely that a single assessment session with a limited set of drug-related cues would do a very good job at accurately measuring the stable trait of cue-specific craving. There are other circumstances where we would also be interested in craving as a trait, for example, in studies of the genetic correlates of craving. ${ }^{62-64}$ Here too, we would want to be assured that we were measuring the stable, context-invariant aspects of craving. The extent to which we can do that adequately in a single assessment session with available instruments is an open question.

The trait-state distinction is related to the time frame targeted by craving assessments. Assessments that ask about the current level of craving (e.g., "What is your craving right now?" ${ }^{65}$ ) are necessarily focused on transient, state levels of craving. To the extent that traits represent the average of state assessments collected over time and context, ${ }^{66}$ trait measures of craving could be derived from multiple administrations of state-oriented craving assessments. That approach, while appealing empirically, is impractical clinically. There are craving assessments that target more stable, trait-like features of craving by asking drug users to rate their craving over time (e.g., "What was your craving over the past week?"67). Although drug users may answer questions like these without hesitation, the extent to which their answers accurately capture average craving levels over extended periods is unclear. Tiffany et al $^{22}$ found that the correlation between the Now version (i.e., current level of craving) and the General version (i.e., craving over the past week) of the Cocaine Craving Questionnaire was extremely high $(r=0.82)$, suggesting that state and trait levels of cocaine 
craving were strongly related (see also Tiffany et al. ${ }^{68}$ ). However, given that both questionnaires were administered at the same time, it is possible that responses to the General version were largely influenced by current levels of craving and did not, in fact, represent the average of craving over the previous week. Given the multiple biases inherent in retrospection and the many difficulties people have in accurately integrating labile psychological states over time and multiple contexts, ${ }^{69}$ any questionnaire that asks drug users to provide an average craving rating over an extended recall period is suspect as a measure of trait levels of craving. Such questionnaires could be properly validated by comparing their scores with scores derived from multiple state questionnaires administered repeatedly over the same period.

\section{Single item, categorical assessment of craving}

Nearly all research on the potential diagnostic utility of craving has relied on single-item instruments with categorical outcomes (i.e., yes/no scales; see Table 1 for examples). These two features of such instruments may limit the reliability and consequent validity of these assessments. With regard to the number of items, the reliability of a single item given in isolation cannot be estimated. But, all things being equal, reliability increases with the number of items. Therefore, a one-item assessment is the least reliable of all possible assessment lengths. (Fortunately, estimates reliably increase in a curvilinear fashion with the addition of items, so if candidate items are at least moderately intercorrelated, reliability can reach fairly high levels with only a few items. ${ }^{70}$ )

With respect to categorical outcomes, a reliability estimate can be thought of as the correlation between observed scores and true scores, and any factor that tends to diminish correlations will have a similar impact on reliabilities. As noted by Cohen, ${ }^{71}$ dichotomization of one variable in a calculation of a correlation dramatically restricts the maximum possible correlation and severely underestimates effect sizes. Similarly, dichotomous response scales also attenuate reliability estimates, particularly when the underlying construct is distributed continuously. ${ }^{72}$

The bottom line is that assessments of craving that rely on only one item with a dichotomous response scale might not achieve the level of reliability generally considered suitable for clinical decisions. Notably, there has been little programmatic research on the practical gain afforded by multi-item craving instruments as opposed to single-item scales or the potential advantages of continuous as opposed to dichotomous craving scales. Nonetheless, given the realities of clinical practice, single-item scales with dichotomous response options are likely to remain the prevailing method for assessing specific features of substance-use disorders, including craving. So, at the very least, more research on the psychometric performance of isolated craving items is needed, particularly when they are intended to inform diagnostic decisions. Interestingly, despite potential shortcomings of single item, dichotomous scales, studies using this measurement approach have fairly consistently supported the diagnostic utility of craving. 


\section{Craving and diagnosis}

Craving is listed as one of the six features of psychoactive substance dependence in the current version of the International Classification of Diseases (ICD-10 $0^{73}$ ). Craving was not listed as a feature of dependence, abuse, or withdrawal in DSM-IV ${ }^{74}$ though it did appear in DSM-III ${ }^{75}$ as a feature of tobacco withdrawal and in DSM-IIIR ${ }^{73}$ as an attribute of both nicotine and opioid withdrawal. ${ }^{76}$ With the pending arrival of DSM-V, craving has reappeared as a proposed criterion for diagnosis of substance-use disorders in the DSM system. ${ }^{77}$ The rationale for this "new" diagnostic criterion offered by the Substance-Related Disorders Workgroup for DSM- $\mathrm{V}^{78}$ was somewhat cursory, with the work-group stating that craving was a common clinical symptom that tended to be present on the high end of the severity spectrum. In addition, they noted that craving has been used frequently as an outcome measure in clinical trials, and that it has been assessed in large population studies as "strong urges for the drug in the past." They also said that brain imaging studies of cuespecific craving have found correlated activity in brain regions associated with reward. Though none of these assertions is controversial, it is not evident how these observations provide a compelling case for the inclusion of craving as a diagnostic criterion for substance-use disorders.

One problem confronting the decision whether or not to include craving as a criterion for substance-use disorders is that there are few explicit guidelines for adding any criterion to an existing diagnosis. Inspection of the literature suggests that five considerations tend to drive diagnostic expansion: (1) practical expediency, for example, aligning the criteria in one system with those present in another with the goal of integrating both systems; ${ }^{79}$ (2) descriptive fidelity, for example, establishing that a candidate criterion is a common feature of the disorder and/or is somewhat unique to the disorder; (3) diagnostic efficiency, for example, demonstrating that the inclusion of a criterion enhances the selectivity and/or specificity of a diagnosis; (4) theoretical integrity, for example, maintaining that the proposed criterion is mandated by the prevailing conceptualization of the disorder or presenting strong evidence that a criterion serves as a taxonic indicator of a disorder $;{ }^{80}$ and (5) clinical feasibility, for example, showing that assessment of the new criterion can be readily implemented in routine clinical practice. ${ }^{81}$ We will discuss how each of these considerations might apply to craving as a criterion for substance-use disorders.

\section{Practical expediency}

As noted, ICD-10 includes craving as a criterion for substance dependence whereas DSMIV does not. Indeed, craving is the only substantive discrepancy in the criterion sets for substance dependence across these two major diagnostic systems. Obviously, the proposed addition of craving to DSM-V would largely reconcile these two diagnostic systems, at least in terms of their descriptive features. Although a few studies have explicitly compared the performance of ICD-10 and DSM-IV, ${ }^{82}$ there are no investigations of the extent to which the craving criterion in ICD is specifically responsible for any discrepancies in the diagnosis of substance dependence between these two systems. The fact that the rates of dependence diagnoses are remarkably concordant across ICD-10 and DSM-IV for most substances ${ }^{82}$ 
suggests that the inclusion of craving in ICD-10 does not produce any major difference in the diagnostic performance of the two systems.

\section{Descriptive fidelity}

Many studies indicate that craving is a common feature of addictive disorders. As one example, more than $90 \%$ of daily cigarette smokers report experiencing at least some craving when they have not smoked for a few hours. ${ }^{8}$ Relatively high rates of craving have also been reported for those diagnosed with cannabis dependence, ${ }^{83}$ methamphetamine-use disorders, ${ }^{84}$ cocaine-use disorders, ${ }^{85}$ and alcohol-use disorders. ${ }^{86}$ Not all studies obtain a high prevalence rate for craving, but this appears to be largely because prevalence estimates can be strongly conditioned by the exact terms used to assess craving. In a major study evaluating the suitability of adding craving to the criterion set for diagnosis of alcohol disorders, Keyes et al. ${ }^{46}$ reported that craving was relatively rare $(1.3 \%$ among current drinkers) compared to other dependence criteria. In their research, craving was assessed with the item "In your entire life, did you ever want a drink so badly that you couldn't think of anything else?" This item captures only a very strong level of craving, so it is not surprising that relatively few people endorsed it. Agrawal et al. ${ }^{87}$ found that craving assessed with the item "feeling a very strong desire to drink" was endorsed by nearly five times as many people as the item "wanting a drink so badly you couldn't think about anything else." These findings indicate that any conclusions about the association of craving with substance-use disorders must take into account the characteristics of the item used to measure craving.

Craving is also somewhat uniquely associated with substance-use disorders, in particular, substance dependence. People without a dependence diagnosis tend not to report that they have experienced craving (e.g., Ref. 87). One way to quantify the extent to which a given criterion differentiates between those with and without dependence is to use the discrimination parameter derived from item-response analyses of sets of candidate criteria. A criterion with relatively higher discrimination more precisely distinguishes between those who are high and low in dependence. Recent studies of alcohol diagnoses have examined the item-response parameters of various criteria (including craving) putatively representative of alcohol-use disorders. ${ }^{33,34,88}$ In each study, the discrimination value associated with craving tended to be relatively high. For example, Mewton et al. ${ }^{34}$ found that the discrimination value for craving was the third highest among 11 criteria. Similarly, Keyes et al. ${ }^{46}$ reported that the discrimination value for craving was the second highest among 12 criteria.

Analyses of the latent structure of diagnostic criteria for substance-use disorders suggests that the dependence construct is, with some exceptions, uni-dimensional (e.g., Refs. 46, and $88-89 ; c f ., 90)$. When craving is included as a variable in these analyses, it typically loads fairly robustly on this "dependence" factor, ${ }^{86,90}$ often with factor loadings that are higher than several other more conventional dependence criteria. ${ }^{47}$ From a factor-analytic perspective, craving can be strongly identified as an important indicator of the dependence construct, or, in line with the diagnostic consideration discussed in this section, craving has high descriptive fidelity with substance dependence. 


\section{Diagnostic efficiency}

Few studies have evaluated the specific impact of a craving criterion on the diagnostic efficiency of extant criterion sets for substance-use disorders. All studies related to this topic examined alcohol diagnoses, ${ }^{46,86,87}$ and each found that the addition of a craving criterion had relatively little impact on prevalence estimates for alcohol-use disorders. Given similar findings in comparisons of the performance of ICD-10 and DSM-IV (which, as noted earlier, differ principally by the presence of craving in the former and not the latter), as well as the strong loading of craving on the general dependence factor, it is hardly surprising that craving would add little incremental validity to diagnoses generated through more conventional dependence criteria.

Some authors have argued that, because craving appears to be largely redundant with other features, it is not a promising candidate as an additional criterion for diagnosis of alcoholuse disorders. ${ }^{46-47,86}$ This conclusion seems unwarranted on several grounds. First, if inclusion of a criterion is to be judged primarily by its incremental validity, then thatargumentshouldbeapplieduniformlytoallcriteria comprising a diagnosis. By that standard, craving might be retained for diagnosis whereas other criteria might be eliminated. Perhaps a higher bar might be set for a criterion not already in the diagnostic set, but, as craving is already represented in ICD-10, a better question might be whether the addition of craving harms the efficiency of a diagnostic system. There is no evidence that this is the case - when craving is added as a criterion, it generates a more discriminating set of diagnostic criteria. ${ }^{46-47,86}$ Second, the redundancy of craving as a criterion, particularly to the extent that it has little impact on prevalence estimates, may be desirable. If the addition of craving had substantially increased the prevalence estimates of alcohol disorders, many might question whether it was a suitable addition to the diagnosis of substance-use disorders. As it stands, research to date suggests that craving can be added with no diagnostic penalty to prevalence estimates. Finally, the "redundancy" of craving is a manifestation of the fact that craving is a strong indicator of an underlying dependence construct. To the extent that dependence is a unidimensional (or unicategorical) construct, then the addition of craving as a criterion may only enhance the coherence of the criterion set used to identify that construct.

\section{Theoretical integrity}

Craving is a central concept in nearly all major contemporary models of drug dependence. ${ }^{5,8}$ In many theories, craving operates as the major motivational substrate for ongoing drug use and is seen as responsible for relapse in people attempting abstinence. ${ }^{25,91-93}$ Other theories argue that, although craving may not be directly responsible for all compulsive drug use, it is a core feature of substance-use disorders. ${ }^{94,95}$ From the viewpoint of these models, a comprehensive description of drug dependence must account for craving, and, accordingly, craving should be included in any listing of dependence attributes. Either theoretical perspective (craving as causal to dependence or craving as descriptively core to dependence), provides ample theoretical support for the inclusion of craving as a critical component in the diagnosis of substance-use disorders. 
Recent research on the taxometrics of dependence provides additional conceptual support for the inclusion of craving as an essential aspect of dependence. Taxometric analysis refers to a family of statistical procedures for evaluating whether multiple indicators presumably indexing a single construct, for example, drug dependence, have a taxonic (categorical) or dimensional latent structure. Evidence of a taxon would indicate that the condition of dependence is qualitatively distinct from the nondependent state- that is, there is a natural boundary between dependent and nondependent drug use. In contrast, evidence of a dimensional latent structure indicates that dependence varies along a continuum with only a quantitative difference between those diagnosed as dependent and those not meeting the threshold for diagnosis. Taxometric analyses allow for the detection of a latent taxon, and, if a taxon is present in the data, it can pinpoint the indicators best suited to identifying that taxon. Goedeker and Tiffany ${ }^{96}$ conducted a series of taxometric analyses on smoking-related data from the National Survey on Drug Use and Health and found robust evidence of a tobacco dependence taxon across all analyses. Important for this paper, one of the indicators identified as a core component of the dependence taxon was a scale defined primarily by craving-related items. For example, the item that correlated most highly with the total scale score was worded, "When you do not smoke for a few hours, you start to crave cigarettes."Othershavereachedasimilarconclusion regarding the value of craving as a core component of tobacco dependence using a different set of analyses to classify cigarette smokers. ${ }^{90}$ That research used latent profile analyses, factor analyses, and factor mixture models to detect a class of tobacco dependence uniquely identified by craving and three other indicators (automaticity, tolerance, and loss of control). These results demonstrate that craving is a fundamental feature of tobacco dependence and may help distinguish dependence as a categorical construct.

\section{Clinical feasibility}

As already described in this paper, craving can be assessed with a high degree of reliability using a relatively small set of self-report items. The research on the utility of craving as a criterion for substance-use disorders indicates that even somewhat crude, categorical, singleitem assessments of craving may perform adequately for diagnostic purposes. By any standard, craving is easy to measure with instruments that can be readily employed in clinical practice.

\section{Recommendations regarding craving as a diagnostic criterion}

All considerations reviewed support the use of craving as a criterion for the diagnosis of substance-use dependence. A major unresolved diagnostic issue is how to best assess craving as a dependence feature. To this point, evaluations of the diagnostic utility of craving have been largely at the mercy of the items embedded in extant large-scale surveys of drug dependence. The psychometric quality of these items was probably not a priority in the development of these questionnaires, and the parent studies from which these data were collected were not designed principally to answer questions about craving. Consequently, most of these studies have assessed craving via single items with untested psychometric characteristics. But the content, complexity, and severity of craving embodied in these items have varied considerably, and those variations can have a marked influence on the operating characteristics of this criterion. Asking "Have you ever craved alcohol?" will likely produce 
different results than asking "Did you ever want a drink so badly that you couldn't think of anything else?" These two examples differ in terms of severity (with the former representing a weaker level of craving than the latter). Moreover, the first item asks only about desire, whereas the second item explicitly invokes a level of desire that disrupts thinking, which is a more complex conceptualization of craving. As it is difficult to anticipate precisely the impact of these variations in item wording on the diagnostic performance of craving assessments, we recommend that program-matic research be conducted on the psychometric performance and diagnostic consequences of candidate craving items. At a minimum, the tested items should cover a wide span of craving severity, have content that reflects the concept of craving as a state ment of desire, and include both dichotomous (i.e., yes/no) and continuous rating scales.

\section{Craving and prognosis}

There is considerable dispute about the extent to which craving is associated with measures of drug-use behavior or predictive of relapse. It is not uncommon to find researchers and reviewers espousing one of two extreme positions on this issue: namely, craving is strongly associated with drug-use behavior, or craving has no meaningful relationship with drug-use behavior. Advocates of either position can readily cite research supporting their opinion. For example, in selected studies, craving has been significantly predictive of drug use and relapse, and this relationship has been observed for all major drugs of abuse. ${ }^{7,10,12,97-104} \mathrm{On}$ the other hand, many studies have not detected significant associations between craving and drug use and/or relapse. ${ }^{22,51,105-108}$ A complete evaluation of the available evidence, pro and con, is beyond the scope of this paper. Recently, however, we have completed a review of the literature relating craving and clinical outcomes in treatment studies for tobacco. ${ }^{109}$ Approximately half of the indexes of association identified in this literature revealed a significant relationship between craving and smoking cessation outcome. Further, even a cursory appraisal of the literature on drugs of abuse beyond nicotine suggests that extreme positions regarding the predictive potential of craving are untenable. That is, there are enough studies with positive results to support the further exploration of the prognostic utility of craving. At the same time, in light of numerous negative findings and the relatively weak relationships even in the case of some positive findings, there is little empirical justification for advocating the widespread use of craving as a robust predictor of relapse. Given the large number of studies that have examined relationships between craving and drug use, we think that a comprehensive, integrative review of the findings on this topic is overdue. Such a review would be most clinically informative if it went beyond the narrow question, "Does craving predict drug-use behavior?" and asked instead "Under what conditions, with what measures, in which people, and to what degree are assessments of craving significantly related to what aspects of drug-use behavior?" Further, although a significant association may be of interest to researchers, unless the relationship is fairly strong and replicable, it will not be of much use to the practicing clinician for generating meaningful predictions. ${ }^{57}$

We believe the prognostic value of craving will only be realized when the factors that moderate the relationships between craving and drug use are identified. As noted by Tiffany et al. " "To the extent those relationships [between craving and drug use] exist, they will be 
strongest when: (a) the measures of craving are highly reliable, (b) the conditions of craving assessment and/or induction are maximally representative of the natural expression of craving, (c) neither craving nor drug-use measures are restricted in range, and (d) evaluations of craving and drug use are conducted in temporal proximity" (pages 180-181). This last point is particularly critical when relapse is the clinical endpoint, as, in most research, craving has been assessed at some point far distant from the relapse episode. As noted earlier in this paper, when the craving-relapse relationship is assessed in this way, we would want to be absolutely certain that our assessment captured the trait aspect of craving, and it is not evident that extant craving instruments accomplish that. Alternatively, we might assess a person's level of craving more proximal to a relapse episode..$^{97,98,100,110}$ Such "state" craving, which presumably varies as a functionof context andother situational conditions, may be a far more sensitive indicator of immediate relapse risk than craving measured days or weeks prior to the current episode.

\section{Craving as a clinical outcome}

Traditionally, the principal outcome in treatment research on substance-use disorders has been reduction in, or elimination of, drug consumption. ${ }^{111}$ But there have been numerous proposals that effective treatments should attend to consequences and features of addiction beyond drug use, and there have been repeated calls for routinely incorporating a common set of "other" outcome measures into treatment research. ${ }^{112-115}$ Craving is one of the more commonly assessed "other outcomes" in treatment research, and there have been multiple recommendations that craving be included as a standard outcome across treatment studies. ${ }^{113}$ Recently, a panel of substance abuse treatment and research experts convened by the National Institute on Drug Abuse discussed appropriate outcome measures for clinical trials of substance-use disorders. ${ }^{113}$ This panel generated specific guidelines for consideration of outcomes and identified five candidates for inclusion as primary outcomes in treatment studies. Craving readily met the inclusion guidelines and was selected as one of the recommended outcomes along with self-efficacy, psychosocial functioning, network support/social support, and quality of life.

\section{Craving as a primary clinical target}

Beyond craving's potential utility as an outcome in treatment research, interventions could be developed to target craving with the expectation that craving relief may be, by itself, a valuable endpoint for addictions therapy. ${ }^{116-119}$ Though subtle, the distinction between craving as a treatment outcome and craving as a clinical target is significant. In the former case, craving would serve as dependent variable for evaluating the outcome of any treatment regardless of the presumed mechanisms of action for the treatment. In the latter case (craving as a clinical target), the intervention would focus on the amelioration of craving under the assumption that craving may directly drive drug use or act as a precursor to relapse. Further, to the extent that craving is viewed as aversive or distressing, it could be a target of treatment irrespective of its ultimate impact on drug use.

The question of whether craving might serve as a target for treatment is not an insular research issue. Recently, the Family Smoking Prevention and Tobacco Control Act of 2009 
(Public Law No: $111-31),{ }^{120}$ which granted authority to the FDA to regulate tobacco products, directed the FDA to "review and consider the evidence for additional indications for nicotine replacement products, such as for craving relief or relapse prevention" [italics added]. Many studies show that treatments for drug use can affect craving. ${ }^{119}$ For example, craving is reduced by FDA-approved medications for various forms of drug dependence including buprenorphine and methadone for opioid dependence, ${ }^{121,122}$ acamprosate and naltrexone for alcohol dependence, ${ }^{123-125}$ and bupropion, nicotine patches, and varenicline for tobacco dependence. ${ }^{126-128}$ Many psychosocial interventions also focus specifically on reducing craving. For instance, cognitive-behavioral treatments typically include training to help drug users avoid or manage their craving. ${ }^{129-132}$ As another prominent example, cueexposure treatments entail the repeated presentation of drug-related cues in an attempt to extinguish cue-specific craving. ${ }^{133}$

Although craving control is at the heart, implicitly or explicitly, of many interventions for substance-use disorders, researchers have rarely examined the extent to which changes in craving over the course of treatment mediate long-term changes in craving or other outcome variables. ${ }^{134-137}$ In some of these studies, changes in craving at least partially mediated the effects of treatments on outcomes. Certainly, more research is necessary to establish the conditions that determine when craving reduction brought about through treatment might mediate long-term positive outcomes. Interestingly, some evidence suggests that the distressing, functionally disruptive consequences of craving may be key to understanding the impact of craving on relapse potential. ${ }^{8}$ There has been almost no research, however, on the extent to which treatments can reduce the aversive qualities of craving and whether such effects are viewed by individuals as offering significant relief. Presumably, a treatment that directly atten uates craving distress would have a positive impact on other outcomes (e.g., promote long-term reductions in drug use or enhance quality of life), though that would need to be determined for each intervention.

\section{Conclusions and recommendations}

Throughout this paper, we have offered a number of proposals, specific suggestions for research, and issues for clinical consideration. These various recommendations are summarized in Table 2. Beyond these points, we believe that the literature supports several conclusions of considerable importance regarding the clinical significance of craving. First, there is substantial uniformity of opinion across addictions researchers regarding the general definition of craving, and this definition is perfectly suitable for both research and clinical activities. Second, craving can be assessed with striking reliability using instruments that are relatively easy to deploy with little burden for either drug users or clinicians. Third, there is strong support, both empirical and conceptual, for the inclusion of craving as a criterion for diagnosis of substance-use disorders, in particular, substance dependence. Fourth, at present, craving is not a clinically consistent predictor of relapse, though the prognostic potential of craving may be enhanced with research identifying the conditions under which craving is more strongly associated with drug use. Fifth, there is considerable support for the routine inclusion of craving as a clinical outcome in treatment research on substance-use disorders. Finally, the value of craving as a direct target of treatment has been too little researched to make definitive clinical recommendations. Nonetheless, initial studies show that craving can 
at times operate as a mediator of treatment outcome, and there is support for more intensive investigations of the impact of treatments that target the aversive properties of craving. On balance, we believe that craving has considerable clinical significance across multiple domains. As research progresses, we expect that the clinical potential of craving will continue to expand.

\section{References}

1. Kozlowski LT, Wilkinson DA. Use and misuse of the concept of craving by alcohol, tobacco, and drug researchers. Addiction. 1987; 82:31-36.

2. Drummond DC, Litten RZ, Lowman C, Hunt WA. Craving research: future directions. Addiction. 2000; 95:247-255.

3. Mello, NK. Behavioural studies of alcoholism.. In: Kissen, B.; Begleiter, H., editors. Physiology and Behaviour. Plenum; New York: 1972. p. 219-291.

4. Pickens RW, Johanson CE. Craving: consensus of status and agenda for future research. Drug Alcohol Depend. 1992; 30:127-131. [PubMed: 1633752]

5. Drummond DC. Theories of drug craving, ancient and modern. Addiction. 2001; 96:33-46. [PubMed: 11177518]

6. Addolorato G, Leggio L, Abenavoli L, et al. Neurobiochemical and clinical aspects of craving in alcohol addiction: a review. Addict. Behav. 2005; 30:1209-1224. [PubMed: 15925129]

7. Ferguson SG, Shiffman S. The relevance and treatment of cue-induced cravings in tobacco dependence. J. Subst. Abuse. Treat. 2009; 36:235-243. [PubMed: 18715743]

8. Tiffany, ST.; Warthen, MW.; Goedeker, KC. The functional significance of craving in nicotine dependence.. In: Bevins, R.; Caggiula, A., editors. Nebraska Symposium on Motivation: The Motivational Impact of Nicotine and its Role in Tobacco Use. The University of Nebraska Press; Lincoln, NE.; 2008. p. 171-197.

9. Anton RF. Obsessive-compulsive aspects of craving: development of obsessive compulsive drinking scale. Addiction. 2000; 95(Suppl. 3):S211-S217. [PubMed: 11002915]

10. Paliwal P, Hyman SM, Sinha R. Craving predicts time to cocaine relapse: further validation of the Now and Brief versions of the cocaine craving questionnaire. Drug Alcohol Depend. 2008; 93:252-259. [PubMed: 18063320]

11. Perkins KA. Does smoking cue-induced craving tell us anything important about nicotine dependence? Addiction. 2009; 104:1610-1616. [PubMed: 19426293]

12. Weiss R, Griffin ML, Mazurik C, et al. The relationship between cocaine craving, psychosocial treatment and subsequent cocaine use. Am. J. Psychiatry. 2003; 160:1320-1325. [PubMed: 12832248]

13. Pavlick M, Hoffmann E, Rosenberg H. A nationwide survey of American alcohol and drug craving assessment and treatment practices. Addict. Res. Theory. 2009; 17:591-600.

14. Rosenberg H. Clinical and laboratory assessment of the subjective experience of drug craving. Clin. Psychol. Rev. 2009; 29:519-534. [PubMed: 19577831]

15. Cox LS, Tiffany ST, Christen AG. Evaluation of the brief questionnaire of smoking urges (QSUBrief) in laboratory and clinical settings. Nicotine Tob. Res. 2001; 3:7-16. [PubMed: 11260806]

16. Anton RF, Moak DH, Latham P. The Obsessive-Compulsive Drinking Scale: a self-rated instrument of the quantification of thoughts about alcohol and drinking behavior. Alcohol. Clin. Exp. Res. 1995; 19:92-99. [PubMed: 7771669]

17. Mezinskis JP, Honos-Webb L, Kropp F, Eugene Somoza E. The measurement of craving. J. Addict. Dis. 2001; 20:67-85. [PubMed: 11681594]

18. Tiffany ST, Carter BL, Singleton EG. Challenges in the manipulation, assessment and interpretation of craving relevant variables. Addiction. 2000; 95:S177-S187. [PubMed: 11002913]

19. Sayette MA, Shiffman S, Tiffany ST, et al. The measurement of drug craving. Addiction. 2000; 95:S189-S210. [PubMed: 11002914] 
20. Anton RF, Drobes DJ. Clinical measurement of craving in addiction. Psychiatr. Ann. 1998; 28:553-560.

21. Tiffany ST. New perspectives on the measurement, manipulation and meaning of drug craving. Hum. Psychopharmacol. 1997; 12:S103-S113.

22. Tiffany ST, Singleton E, Haertzen C, Henningfield JE. The development of a cocaine craving questionnaire. Drug Alcohol Depend. 1993; 34:19-28. [PubMed: 8174499]

23. Kelley, TL. Interpretation of Educational Measurements. Macmillan; New York: 1927.

24. Boorsboom D, Mellenbergh GJ, van Heerden J. The concept of validity. Psychol. Rev. 2004; 111:1061-1071. [PubMed: 15482073]

25. Robinson TE, Berridge KC. Addiction. Annu. Rev. Psychol. 2003; 54:25-53.

26. Brody AL, Mandelkern MA, London ED, et al. Brain metabolic changes during cigarette craving. Arch. Gen. Psychiatry. 2002; 59:1162-1172. [PubMed: 12470133]

27. McClernon FJ, Hiott FB, Huettel SA, Rose JE. Abstinence-induced changes in self-report craving correlate with event-related FMRI responses to smoking cues. Neuropsychopharmacol. 2005; 30:1940-1947.

28. Grant S, London ED, Newlin DB, et al. Activation of memory circuits during cue-elicited cocaine craving. Proc. Natl. Acad. Sci. 1996; 93:12040-12045. [PubMed: 8876259]

29. Naqvi NH, Bechara A. The insula and drug addiction: an interoceptive view of pleasure, urges, and decision-making. Brain. Struct. Funct. 2010; 214:435-450. [PubMed: 20512364]

30. Nora D, Volkow ND, Wang GJ, et al. Addiction circuitry in the human brain. Annu. Rev. Pharmacol. Toxicol. 2012; 52:321-36. [PubMed: 21961707]

31. Center for Drug Evaluation and Research. [22 July] Approval Package For Application Number 21-928. 2011. Available at: http://www.accessdata.fda.gov/drugsatfdaGMKdocs/nda/ 2006/021928GMKs000GMKChantixGMKAdminCorres.pdf.

32. Beck, AT.; Steer, RA.; Brown, GK. Manual for the Beck Depression Inventory-II. Psychological Corp; San Antonio, TX.: 1996. p. 38

33. Kozlowski LT, Pillitteri JL, Sweeney CT, et al. Asking questions about urges or cravings for cigarettes. Psychol. Addict. Behav. 1996; 10:248-260.

34. Tiffany ST, Drobes DJ. The development and initial validation of a questionnaire on smoking urges. Br. J. Addict. 1991; 86:1467-1476. [PubMed: 1777741]

35. Bohn MJ, Barton BA, Barron KE. Psychometric properties and validity of the ObsessiveCompulsive Drinking Scale. Alcohol Clin. Exp. Res. 1996; 20:817-823. [PubMed: 8865954]

36. de Wildt WA, Lehert P, Schippers GM, et al. Investigating the structure of craving using structural equation modeling in analysis of the obsessive-compulsive drinking scale: a multinational study. Alcohol Clin. Exp. Res. 2005; 29:509-516. [PubMed: 15834215]

37. Kranzler HR, Mulgrew CL, Modesto-Lowe V, Burleson JA. Validity of the Obsessive Compulsive Drinking Scale (OCDS): does craving predict drinking behavior? Alcohol Clin. Exp. Res. 1999; 23:108-114. [PubMed: 10029210]

38. Roberts JS, Anton RF, Latham PK, Moak DH. Factor structure and predictive validity of the Obsessive Compulsive Drinking Scale. Alcohol Clin. Exp. Res. 1999; 23:1484-1491. [PubMed: 10512314]

39. Kim MJ, Kim SG, Kim HJ, et al. A study of the reliability and validity of the Korean Version of the Penn Alcohol Craving Scale for alcohol-dependent patients. Psychiatry Investig. 2008; 5:175178.

40. Ooteman W, Koeter MW, Verheul R, et al. Measuring craving: an attempt to connect subjective craving with cue reactivity. Alcohol Clin. Exp. Res. 2006; 30:57-69. [PubMed: 16433732]

41. Heishman SJ, Singleton EG, Liguori A. Marijuana Craving Questionnaire: development and initial validation of a self-report instrument. Addiction. 2001; 96:1023-1034. [PubMed: 11440613]

42. Heishman SJ, Evans RJ, Singleton EG, et al. Reliability and validity of a short form of the Marijuana Craving Questionnaire. Drug Alcohol Depend. 2009; 102:35-40. [PubMed: 19217724]

43. Heishman SJ, Singleton EG, Pickworth WB. Reliability and validity of a short form of the Tobacco Craving Questionnaire. Nicotine Tob. Res. 2008; 10:643-651. [PubMed: 18418787] 
44. Kessler RC, Wittchen HU, Abelson JM, et al. Methodological studies of the Composite International Diagnostic Interview (CIDI) in the US National Comorbidity Survey. Int. J. Methods Psychiatr. Res. 1998; 7:33-55.

45. Miele GM, Carpenter KM, Cockerham MS, et al. Concurrent and predictive validity of the Substance De pendence Severity Scale (SDSS). Drug Alcohol Depend. 2000; 59:77-88. [PubMed: 10706977]

46. Keyes KM, Krueger RF, Grant BF, Hasin DS. Alcohol craving and the dimensionality of alcohol disorders. Psychol. Med. 2011; 41:629-640. [PubMed: 20459881]

47. Mewton L, Slade T, McBride O, Teesson M. An evaluation of the proposed DSM-5 alcohol use disorder criteria using Australian national data. Addiction. 2011; 106:941-950. [PubMed: 21205055]

48. Grant, BF.; Dawson, D. The Alcohol Use Disorder and Associated Disabilities Interview ScheduleIV (AUDADIS-IV). National Institute on Alcohol Abuse and Alcoholism; Rockville, MD.: 2000.

49. Bucholz KK, Cadoret R, Cloninger CR, et al. Semi-structured psychiatric interview for use in genetic linkage studies: a report on the reliability for the SSAGA. J. Stud. Alcohol. 1994; 55:149158. [PubMed: 8189735]

50. Brandon, TH.; Juliano, LM.; Copeland, AL. Expectancies for tobacco smoking.. In: Kirsch, I., editor. InHow Expectancies Shape Experience. American Psychological Association; Washington, DC.: 1999. p. 263-299.

51. Whitely SE. Construct validity: construct representation versus nomothetic span. Psychol. Bull. 1983; 93:179-197.

52. Flannery BA, Volpicelli JR, Pettinati HM. Psychometric properties of the Penn Alcohol Craving Scale. Alcohol Clin. Exp. Res. 1999; 23:1289-1295. [PubMed: 10470970]

53. Halikas JA, Kuhn KL, Crosby R, et al. The measurement of craving in cocaine patients using the Minnesota cocaine craving scale. Compr. Psychiatry. 1991; 32:22-27. [PubMed: 2001617]

54. Weiss RD, Griffin ML, Hufford C. Craving in hospitalized cocaine abusers as a predictor of outcome. Am. J. Drug Alcohol Abuse. 1995; 21:289-301. [PubMed: 7484980]

55. Florsheim P, Shiozaki T, Hiraoka R, et al. Craving among polysubstance-using adolescents. J. Child Adolesc. Subst. Abuse. 2007; 17:101-124.

56. Peterson RA. A meta-analysis of Cronbach's coefficient alpha. J. Consum. Res. 1994; 21:381-391.

57. Nunnally, J.; Bernstein, I. Psychometric Theory. 3rd ed.. McGraw Hill; New York: 1994.

58. Streiner DL. Starting at the beginning: an introduction to coefficient alpha and internal consistency. J. Pers. Assess. 2003; 80:99-103. [PubMed: 12584072]

59. Caruso JC. Reliability generalization of the NEO personality scales. Educ. Psychol. Meas. 2000; 60:236-254.

60. LaRowe SD, Saladin ME, Carpenter MJ, Upadhyaya HP. Reactivity to nicotine cues over repeated cue reactivity sessions. Addict. Behav. 2007; 32:2888-2899. [PubMed: 17537583]

61. Raabe A, Grüsser SM, Wessa M, et al. The assessment of craving: psychometric properties, factor structure and a revised version of the Alcohol Craving Questionnaire (ACQ). Addiction. 2005; 100:227-234. [PubMed: 15679752]

62. Erblich J, Lerman C, Self DW, et al. Stress induced cigarette craving: effects of the DRD2 TaqI RFLP and SLC6A3 VNTR polymorphisms. Pharmacogenomics J. 2004; 4:102-109. [PubMed: 14732864]

63. Ray LA. Stress-induced and cue-induced craving for alcohol in heavy drinkers: preliminary evidence of genetic moderation by the OPRM1 and CRH-BP genes. Alcohol. Clin. Exp. Res. 2011; 35:166-174. [PubMed: 21039637]

64. van den Wildenberg E, Wiers RW, Dessers J, et al. A functional polymorphism of the mu-opioid receptor gene (OPRM1) influences cue-induced craving for alcohol in male heavy drinkers. Alcohol. Clin. Exp. Res. 2007; 31:1-10. [PubMed: 17207095]

65. Powell J, Dawkins L, West R, et al. Relapse to smoking during unaided cessation: clinical, cognitive, and motivational predictors. Psychopharmacology. 2010; 212:537-549. [PubMed: 20703450] 
66. Zuckerman, M. General and situation-specific traits and states: new approaches to assessment of anxiety and other constructs.. In: Zuckerman, M.; Spielberger, CD., editors. Emotion and Anxiety: New Concepts, Methods, and Applications. Erlbaum; Hillsdale, NJ.: 1976. p. 133-174.

67. Kaufmann V, Jepson C, Rukstalis M, et al. Subjective effects of an initial dose of nicotine nasal spray predict treatment outcome. Psychopharmacology. 2004; 172:271-276. [PubMed: 14647969]

68. Tiffany ST, Fields L, Singleton E, et al. The development of a heroin craving questionnaire. 1993 Unpublished manuscript.

69. Hammersley R. A digest of memory phenomena for addiction research. Addiction. 1994; 89:283293. [PubMed: 8173494]

70. Cortina JM. What is coefficient alpha? An examination of theory and applications. J. Appl. Psychol. 1993; 78:98-104.

71. Cohen J. The cost of dichotomization. Appl. Psychol. Meas. 1983; 7:249-253.

72. Donner A, Eliasziw M. Statistical implications of the choice between a dichotomous or continuous trait in studies of interobserver agreement. Biometrics. 1994; 50:550-555. [PubMed: 19405213]

73. World Health Organization. The ICD-10 Classification of Mental and Behavioural Disorders: Clinical Descriptions and Diagnostic Guidelines. WHO Press; Geneva: 1992.

74. American Psychiatric Association. Diagnostic and Statistical Manual of Mental Disorders, Fourth Edition (DSM-IV). American Psychiatric Association; Washington, DC.: 1994.

75. American Psychiatric Association. Diagnostic and Statistical Manual of Mental Disorders, Third Edition (DSM-III). American Psychiatric Association; Washington, DC.: 1980.

76. American Psychiatric Association. Diagnostic and Statistical Manual of Mental Disorders, Third Edition - Revised (DSM-IIIR). American Psychiatric Association; Washington: 1987.

77. American Psychiatric Association DSM-5 Development. [July 1, 2011] Substance related disorders. 2010. Available at: http://www.dsm5.org/ProposedRevisions/Pages/SubstanceRelatedDisorders.aspx.

78. American Psychiatric Association DSM-5 Development. [1 July 2011] Rationale for changes to substance-related disorders. 2010. Available at: http://www.dsm5.org/ProposedRevision/Pages/ proposedrevision.aspx? rid $=431 \#$.

79. Kupfer DJ, Regier DA, Kuhl EA. On the road to DSM-V and ICD-11. Eur Arch Psychiatry Clin Neurosci. 2008; 258(Suppl. 5):2-6. [PubMed: 18985287]

80. Ruscio, J.; Haslam, N.; Ruscio, AM. Introduction to the Taxometric method: A Practical Guide. Erlbaum; London: 2006.

81. Kendler, K.; Kupfer, D.; Narrow, W., et al. [1 July 2011] Guidelines for making changes to DSMV. 2009. Available at: http://www.dsm5.org/ProgressReports/Documents/Guidelines-for-MakingChanges-to-DSMGMK1.pdf.

82. Hasin D, Hatzenbuehler ML, Keyes K, Ogburn E. Substance use disorders: Diagnostic and Statistical Manual of Mental Disorders, fourth edition (DSM-IV) and International Classification of Diseases, tenth edition (ICD-10). Addiction. 2006; 101(Suppl. 1):59-75. [PubMed: 16930162]

83. Swift W, Hall W, Teeson M. Characteristics of DSM-IV and ICD-10 cannabis dependence among Australian adults: results from the National Survey of Mental Health and Wellbeing. Drug Alcohol Depend. 2001; 63:147-153. [PubMed: 11376919]

84. Galloway GP, Singleton EG, Buscemi R, et al. An examination of drug craving over time in abstinent methamphetamine users. Am. J. Addict. 2010; 19:510-514. [PubMed: 20958846]

85. Sussner BD, Smelson DA, Rodrigues $\mathrm{S}$, et al. The validity and reliability of a brief measure of cocaine craving. Drug Alcohol Depend. 2006; 83:233-237. [PubMed: 16384655]

86. Cherpitel CJ, Borges G, Ye Y, et al. Performance of a craving criterion in DSM alcohol use disorders. J. Stud. Alcohol Drugs. 2010; 71:674-684. [PubMed: 20731972]

87. Agrawal A, Heath AC, Lynskey MT. DSM-IV to DSM-5: the impact of proposed revisions on diagnosis of alcohol use disorders. Addiction. 106:1935-1943.

88. Borges G, Cherpitel CJ, Ye Y, et al. Threshold and optimal cut-points for alcohol use disorders among patients in the emergency department. Alcohol. Clin. Exp. Res. 2011; 35:1270-1276.

[PubMed: 21352249] 
89. Rounsaville BJ, Bryant K, Babor T, et al. Cross system agreement for substance use disorders: DSM-III-R, DSMIV and ICD-10. Addiction. 1993; 88:337-348. [PubMed: 8461851]

90. Piper ME, Bolt DM, Kim SY, et al. Refining the tobacco dependence phenotype using the Wisconsin Inventory of Smoking Dependence Motives (WISDM). J. Abnorm. Psychol. 2008; 117:747-761. [PubMed: 19025223]

91. Baker, TB.; Morse, E.; Sherman, JE. The motivation to use drugs: a psychobiological analysis of urges.. In: Rivers, PC., editor. In The Nebraska Symposium on Motivation: Alcohol and Addictive Behavior. University of Nebraska Press; Lincoln, NE.: 1987. p. 257-323.

92. Ludwig AM, Wikler A, Stark LH. The first drink: psychobiological aspects of craving. Arch. Gen. Psychiatry. 1974; 30:539-547. [PubMed: 4131353]

93. Wise RA. The neurobiology of craving: implications for understanding and treatment of addiction. J. Abnorm. Psychol. 1988; 97:118-132. [PubMed: 3290303]

94. Baker TB, Piper ME, McCarthy DE, et al. Addiction motivation reformulated: an affective processing model of negative reinforcement. Psychol. Rev. 2004; 1:33-51. [PubMed: 14756584]

95. Tiffany ST. A cognitive model of drug urges and drug use behavior: role of automatic and nonautomatic processes. Psychol. Rev. 1990; 97:147-168. [PubMed: 2186423]

96. Goedeker KC, Tiffany ST. On the nature of nicotine addiction: a taxometric analysis. J. Abnorm. Psychol. 2008; 117:896-909. [PubMed: 19025235]

97. Allen SS, Bade T, Hatsukami D, Center B. Craving, withdrawal, and smoking urges on days immediately prior to smoking relapse. Nicotine Tob. Res. 2008; 10:35-45. [PubMed: 18188743]

98. Epstein DH, Marrone GF, Heishman SJ, et al. Tobacco, cocaine, and heroin: craving and use during daily life. Addict. Behav. 2010; 35:318-324. [PubMed: 19939575]

99. Fidler JA, Shahab L, West R. Strength of urges to smoke as a measure of severity of cigarette dependence: comparison with the Fagerstrom Test for Nicotine Dependence and its components. Addiction. 2011; 106:631-638. [PubMed: 21134020]

100. Hartz DT, Frederick-Osborne SL, Galloway GP. Craving predicts use during treatment for methamphetamine dependence: a prospective, repeated-measures, within-subject analysis. Drug Alcohol Depend. 2001; 63:269-276. [PubMed: 11418231]

101. Killen JD, Fortmann SP. Craving is associated with smoking relapse: findings from three prospective studies. Exp. Clin. Psychopharmacol. 1997; 5:137-142. [PubMed: 9234050]

102. Oslin DW, Cary M, Slaymaker V, et al. Daily ratings measures of alcohol craving during an inpatient stay define subtypes of alcohol addiction that predict subsequent risk for resumption of drinking. Drug Alcohol Depend. 2009; 103:131-136. [PubMed: 19443131]

103. Preston KL, Vahabzadeh M, Schmittner J, et al. Cocaine craving and use during daily life. Psychopharmacology. 2009; 207:291-301. [PubMed: 19777216]

104. Rohsenow DJ, Martin RA, Eaton CA, Monti PM. Cocaine craving as a predictor of treatment attrition and outcomes after residential treatment for cocaine dependence. J. Stud. Alcohol Drugs. 2007; 68:641-648. [PubMed: 17690796]

105. Abrams DB, Monti PM, Carey KB, et al. Reactivity to smoking cues and relapse: two studies of discriminant validity. Behav. Res. Ther. 1988; 26:225-233. [PubMed: 3408457]

106. Rohsenow DJ, Monti PM, Rubonis AV, et al. Cue reactivity as a predictor of drinking among male alcoholics. J. Consult. Clin. Psychol. 1994; 62:620-626. [PubMed: 8063989]

107. Shadel WG, Niaura R, Abrams DB, et al. Scripted imagery manipulations and smoking cue reactivity in a clinical sample of self-quitters. Exp. Clin. Psychopharmacol. 1998; 6:179-186. [PubMed: 9608350]

108. Walton MA, Blow FC, Bingham CR, Chermack ST. Individual and social/environmental predictors of alcohol and drug use 2 years following substance abuse treatment. Addict. Behav. 2003; 28:627-642. [PubMed: 12726780]

109. Wray JM, Tiffany S. A systematic review of the relationships between craving and smoking cessation outcome. 2011 Under review.

110. Shiffman S, Engberg J, Paty JA, et al. A day at a time: predicting smoking lapse from daily urge. J. Abnorm. Psychol. 1997; 106:104-116. [PubMed: 9103722] 
111. Donovan D, Bigelow G, Carroll K, et al. Primary outcome indices in illicit drug dependence treatment research: systematic approach to selection and measurement of drug use endpoints in clinical trials. Addiction. In press.

112. Tai, B. Clinical Decision Network of Cocaine Addiction Pharmacotherapy, Workshop II: Outcome Measures \& Efficacy Criteria Summary Report. National Institutes of Health, National Institute on Drug Abuse; Rockville, MD.: 1993.

113. Tiffany ST, Friedman L, Greenfield SF, et al. Beyond drug use: a systematic consideration of other outcomes in evaluations of treatments for substance use disorders. Addiction. In press.

114. Van den Brink W, Montgomery SA, Van Ree JM, van Zwieten-Boot BJ. ECNP consensus meeting March 2003 Guidelines for the investigation of efficacy in substance use disorders. Eur. Neuropsychopharmacol. 2006; 16:224-230. [PubMed: 16442270]

115. Wells EA, Hawkins JD, Catalano RF. Choosing drug use measures for treatment outcome studies. I. The influence of measurement approach on treatment results. Int. J. Addict. 1988; 23:851-873. [PubMed: 3066766]

116. Addolorato G, Abenavoli L, Leggio L, Gasbarrini G. How many cravings? Pharmacological aspects of craving treatment in alcohol addiction: a review. Neuropsychobiology. 2005; 51:5966. [PubMed: 15741745]

117. Fareed A, Vayalapalli S, Casarella J, et al. Heroin anticraving medications: a systematic review. Am. J. Drug Alcohol Abuse. 2010; 36:332-341. [PubMed: 20955107]

118. Heilig M, Egli M. Pharmacological treatment of alcohol dependence: target symptoms and target mechanisms. Pharmacol. Ther. 2006; 111:855-876. [PubMed: 16545872]

119. O'Brien CP. Anticraving medications for relapse prevention: a possible new class of psychoactive medications. Am. J. Psychiatry. 2005; 162:1423-1431. [PubMed: 16055763]

120. [1 July 2011] Public Law 111-31-JUNE 22, 2009. Available at: http://frwebgate.access.gpo.gov/ cgi-bin/getdoc.cgi?dbname=111_cong_public_laws\&docid=f:publ031.111.pdf.

121. Greenwald MK. Early impact of methadone induction for heroin dependence: differential effects of two dose sequences in a randomized controlled study. Exp. Clin. Psychopharmacol. 2006; 14:52-67. [PubMed: 16503705]

122. Greenwald MK, Schuh KJ, Hopper J, et al. Effects of buprenorphine sublingual tablet maintenance on opioid drug-seeking behavior by humans. Psychopharmacology. 2002; 160:344352. [PubMed: 11919661]

123. Anton RF, Oroszi G, O'Malley S, et al. Combined pharmacotherapies and behavioral interventions for alcohol dependence the COMBINE study: a randomized controlled trial. J. Am. Med. Assoc. 2006; 295:2003-2017.

124. Chick J, Anton R, Checinski K, et al. A multicentre, randomized, double-blind, placebocontrolled trial of naltrexone in the treatment of alcohol dependence or abuse. Alcohol Alcohol. 2000; 35:587-593. [PubMed: 11093966]

125. Chick J, Howlett H, Morgan MY, Ritson B. United Kingdom Multicentre Acamprosate Study (UKMAS): a 6-month prospective study of acamprosate versus placebo in preventing relapse after withdrawal from alcohol. Alcohol Alcohol. 2000; 35:176-187. [PubMed: 10787394]

126. Durcan MJ, Deener G, White J, et al. The effect of bupropion sustained-release on cigarette craving after smoking cessation. Clin. Ther. 24:540-551. [PubMed: 12017399]

127. Jorenby DE, Hays JT, Rigotti NA, et al. Efficacy of varenicline, an alpha4beta2 nicotinic acetylcholine receptor partial agonist, vs placebo or sustained release bupropion for smoking cessation: a randomized controlled trial. J. Am. Med. Assoc. 2006; 296:56-63.

128. Russell MAH, Stapleton JA, Feyerabend C, et al. Targeting heavy smokers in general practice: randomised controlled trial of transdermal nicotine patches. Br. Med. J. 1993; 306:1308-1312. [PubMed: 8518572]

129. Beck, AT.; Wright, FD.; Newman, CF.; Liese, BS. Cognitive Therapy of Substance Abuse. Guilford Press; New York: 1993.

130. Marlatt, GA.; Gordon, JR. Relapse Prevention: Maintenance Strategies in the Treatment of Addictive Behaviors. Guilford; New York: 1985.

131. Monti, PM.; Abrams, DB.; Kadden, RM.; Cooney, NL. Treating Alcohol Dependence: A Coping Skills Training Guide. Guilford Press; New York: 1989. 
132. Perkins, KA.; Conklin, CA.; Levine, MD. Cognitive-Behavioral Therapy for Smoking Cessation: A Practical Guidebook to the Most Effective Treatments. Routledge; New York: 2008.

133. Conklin CA, Tiffany ST. Applying extinction research and theory to cue-exposure addiction treatments. Addiction. 2002; 97:155-167. [PubMed: 11860387]

134. Ferguson SG, Shiffman S, Gwaltney CJ. Does reducing withdrawal severity mediate nicotine patch efficacy? A randomized clinical trial. J. Consult. Clin. Psychol. 2006; 74:1153-1161. [PubMed: 17154744]

135. McCarthy DE, Piasecki TM, Lawrence DL, et al. Psychological mediators of bupropion sustained-release treatment for smoking cessation. Addiction. 2008; 103:1521-1533. [PubMed: 18783504]

136. Piper ME, Federman EB, McCarthy DE, et al. Using mediational models to explore the nature of tobacco motivation and tobacco treatment effects. J. Abnorm. Psychol. 2008; 117:94-105. [PubMed: 18266488]

137. Witkiewitz K, Bowen S, Villarael N, Donovan D. The relation between changes in negative mood and heavy drinking: moderating effects of a craving intervention. J. Consult. Clin. Psychol. 2011; 79:54-63. [PubMed: 21261434] 


\section{Table 1}

Examples of craving items from diagnostic instruments

\begin{tabular}{|c|c|}
\hline Source & Craving item \\
\hline $\begin{array}{l}\text { The University of Michigan Composite } \\
\text { International Diagnostic Interview (UMCIDI) }{ }^{44}, *\end{array}$ & $\begin{array}{l}\text { Was there ever a time in your life when you often had such a strong desire to drink that } \\
\text { you couldn't resist taking a drink or found it difficult to think of anything else? }\end{array}$ \\
\hline Substance Dependence Severity Scale (SDSS) ${ }^{45}$ & A strong desire or sense of compulsion to take the substance. \\
\hline $\begin{array}{l}\text { The 1991-1992 National Longitudinal Alcohol } \\
\text { Epidemiologic Survey (NLAES) }\end{array}$ & $\begin{array}{l}\text { In your entire life, did you ever want a drink so badly that you couldn't think of anything } \\
\text { else? }\end{array}$ \\
\hline $\begin{array}{l}1997 \text { Australian National Survey of Mental } \\
\text { Health and Well-Being (NSMHWB })^{47,},\end{array}$ & $\begin{array}{l}\text { In the past } 12 \text { months, was there a time when you felt such a strong desire or urge to drink } \\
\text { that you could not keep from drinking, or that you wanted a drink so badly you could not } \\
\text { think of anything else? }\end{array}$ \\
\hline $\begin{array}{l}\text { Alcohol Use Disorder and Associated Disabilities } \\
\text { Interview Schedule-Fourth Edition (AUDADIS- } \\
\text { IV })^{48}\end{array}$ & $\begin{array}{l}\text { Since your last interview, did you want a drink so badly that you couldn't think of anything } \\
\text { else? } \\
\text { Since your last interview, did you feel a very strong desire or urge to drink? }\end{array}$ \\
\hline $\begin{array}{l}\text { Semi-Structured Assessment for the Genetics Of } \\
\text { Alcoholism (SSAGA) }\end{array}$ & $\begin{array}{l}\text { In situations where you couldn't drink, did you ever have such a strong desire for it that } \\
\text { you couldn't think of anything else? }\end{array}$ \\
\hline
\end{tabular}

${ }^{a}$ Adapted from the World Health Organization Composite International Diagnostic Interview (CIDI). 


\section{Table 2}

\section{Summary of recommendations}

\begin{tabular}{|c|c|}
\hline Topic & Specific proposals, research suggestions, clinical considerations \\
\hline Definition of craving & Craving is a subjective experience of wanting to use a drug. \\
\hline \multirow[t]{2}{*}{ Content of assessments } & Craving assessments need not include an item referencing the word craving. \\
\hline & Craving assessments should include items referring specifically to synonyms of desire. \\
\hline Conditions of assessment & $\begin{array}{l}\text { Psychometric characteristics of craving assessments must be established under the conditions and groups of } \\
\text { individuals for which the assessment is to be used. }\end{array}$ \\
\hline \multirow[t]{3}{*}{ Reliability and stability } & Reliability should be established for the clinical setting under consideration. \\
\hline & Researchers should always report the reliability of their craving measures calculated from their research sample. \\
\hline & $\begin{array}{l}\text { Questionnaires that ask for average craving ratings over an extended recall period are suspect as measures of trait } \\
\text { levels of craving. }\end{array}$ \\
\hline Diagnosis & $\begin{array}{l}\text { Programmatic research should be conducted on the psychometric performance and diagnostic consequences of } \\
\text { craving items proposed for diagnostic instruments. }\end{array}$ \\
\hline Prognosis & Factors that moderate the relationships between craving and drug use should be identified. \\
\hline Clinical outcome & Craving should be routinely included as a clinical outcome in research on treatments for substance-use disorders. \\
\hline \multirow[t]{2}{*}{ Clinical target } & $\begin{array}{l}\text { Research is needed to establish the conditions under which changes in craving during treatment mediate long-term } \\
\text { outcomes. }\end{array}$ \\
\hline & $\begin{array}{l}\text { Research should evaluate the extent to which treatments provide clinically significant relief from the aversive } \\
\text { qualities of craving. }\end{array}$ \\
\hline
\end{tabular}

